\title{
Los orígenes filosóficos del Romanticismo. La naturaleza como epopeya inconsciente
}

\section{Philosophical origins of Romanticism. Nature as an unconscious epopee}

\author{
JOSÉ LUIS YEPES HITA \\ IES. Alfonso X El Sabio, Murcia (España)
}

Recibido: 10/11/12 Aprobado: 10/07/13

\begin{abstract}
RESUMEN
La historia de las ideas y de la cultura considera el romanticismo un movimiento estético y literario, sin embargo su origen responde a una cuestión esencial de la Filosofía, con una actitud altamente contestataria contra las formas políticas establecidas y la educación recibida de la generación anterior. Traer el romanticismo al academicismo del aula fue la forma de desactivar su fuerza. La búsqueda de una edad heroica, determinó una concepción del tiempo y su proceso civilizador opuesta a la pretensión ilustrada de progreso. El primer precedente es Hamann, una teología crítica alimentada por el pietismo que interiorizó a la vez el empirismo de Hume. Con Herder la Naturaleza se convierte en medio y fin de la nueva educación, recuperando de alguna manera lo que fue el radicalismo de Rousseau. Para Kant, aquella moda era estridente, sin embargo comprendió de ellos las aporías de un finalismo organicista de la Naturaleza y la incapacidad de explicar este proceso desde el determinismo físico laplaciano, vigente en las ciencias experimentales. Frente a la casuística externalista, la libertad se convierte en la esencia de lo humano. Esto apasionó a los románticos. Para Schiller es el motor de la historia humana, que está por encima de la historia natural —el Espíritu, según Hegel—. Este fue el contexto de la Filosofía que Fichte enseñaba, el idealismo: el deber de acción es anterior al propio deber moral. Y esta es la Filosofía de los «años de formación» de Schelling, los Naturphilosophen y el mismo Hegel. La voluntad de acción de la Filosofía fichteana es en Novalis y Hölderlin una «fuerza insconsciente». Contemplan el sublime proceso de la Naturaleza, como una transposición de su propia juventud vivida, de la contradicción y devenir de su propia psique: la
\end{abstract}

(C) Contrastes. Revista Internacional de Filosofia, vol. XIX-Nº1 (2014), pp. 103-122. ISSN: 1136-4076 Departamento de Filosofía, Universidad de Málaga, Facultad de Filosofía y Letras Campus de Teatinos, E-29071 Málaga (España) 
crianza que supera años e incorpora etapas. Por eso Hegel apunta en su semestre de 1805/06, la Realphilosophie: «¿La Tierra tiene una historia? ¿Qué es historia?».

PALABRAS CLAVE

ROMANTICISMO, ENLIGHTENMENT, PEDAGOGÍA, NATURPHILOSOPHIE, HISTORIA NATURAL, ERZIEHUNGSROMAN, BILDUNGSROMAN, HAMANN, HERDER, KANT, FICHTE, GOETHE, SCHILLER, SCHELLING, NOVALIS, HEGEL, HÖLDERLIN

\begin{abstract}
The history of ideas and culture considers Romanticism a literary and aesthetic movement. However, it arises as the answer to an essential question for Philosophy, showing a highly rebellious attitude against both the established political manners and the education received from the previous generation. Bringing out Romanticism and academic formalism was the way to deactivate their strength. The search for a heroic age determined a conception of time and its civilizing process which was opposed to the enlightened aspiration of progress. The first precedent is Hamann, with a critical theology that was fostered by pietism which, at the same time, embraced the idea of empiricism coined by Hume. For Herder, Nature becomes means and aim of the new education, recovering somehow the original meaning of radicalism in Rousseau. For Kant, that was a loud fashion. However, he learnt from them the aporias of an organicist finality of Nature and the inability to explain this process from the physical determinism of Laplace, which was still used in experimental sciences. Opposed to the externalist casuistry, freedom becomes the essence of human nature. Romantics were fascinated by this idea. For Schiller, it is the driving force of human history, which is above natural history - the Spirit, according to Hegel -. This was the context of the philosophe Fichte taught, idealism:the duty of action is prior to the moral duty itself. And this is the philosophy of the so called «training years» of Schelling, the Naturphilosophen and Hegel himself. The will of acting in the philosophy of Fichte is an unconscious force for Novalis and Hölderlin. They consider the sublime process of Nature a transposition of their own youth, of the contradiction and evolution of their own psyche: the breeding that goes over years and adds new stages. This is why Hegel points out, in his semester 1805/06, Realphilosophie: «Does Earth have a history? What is history?» KEY WORDS

ROMANTICISM, ENLIGHTENMENT, PEDAGOGY, NATURPHILOSOPHIE, NATURAL HISTORY, ERZIEHUNGSROMAN, BILDUNGSROMAN, HAMANN, HERDER, KANT, FICHTE, GOETHE, SCHILLER, SCHELLING, NOVALIS, HEGEL, HÖLDERLIN
\end{abstract}

EL ROMANTICISMO significa uno de los mayores cambios ocurridos en la conciencia europea. Antes que nada fue un movimiento filosófico. Como transformación del pensamiento de la civilización occidental sigue en cierta manera vigente aún hoy. Surgió en aquel puzzle de ducados alemanes, naufragio político del Sacro Imperio, cuando el «simbólico» emperador ya sólo se ocupaba de sus asuntos italianos y de sí mismo. Sucedió también en disonancia con la filosofía 
hegemónica y sólo tras el auge de Napoleón y su gran efecto «mediático». ${ }^{1}$ Napoleón creó la Confederación de los Estados del Rhin y aplicó en ellos el nuevo Derecho civil. Aquellos Estados tomaran conciencia de su raíz común, al menos de manera popular, nunca institucionalmente. Es esta otra escisión, emocional, que se sumó intrínsecamente a la anterior.

\section{LA FILOSOFÍA}

En Filosofía dominaba un modelo geométrico que infundió a la educación axiomas infalibles existentes por sí. Una lógica estricta permitiría deducir absolutos, como un remedo de la Gramatica Generalis de Lulio. La matemática generó el optimismo de que podríamos alcanzar un saber absoluto -era el anhelo de universalidad que no tenían-. Su seguro método extirparía tanto la ignorancia como los delirios humanos. Tales programas se presentaron como libertadores, pero terminaron por esclavizar.

Los planes de reforma de la Ilustración, inspirados en el logocentrismo humanista, resultaron extraños, porque la percepción del deber, la noción de pecado y expiación que hay en la cultura judeocristiana, son difícilmente traducibles a análisis racionalistas como los que Aristóteles hace en el De Anima o en la Ética a Nicómaco.

El romanticismo irrumpió en medio con verdaderos tintes de revolución; pasó deprisa y nada volvió a ser igual. Frente a la coherencia del siglo de paz de las Luces, los románticos no rehuyeron la contradicción y atendieron a las deformaciones monstruosas que se desviaban del supuesto diseño de la naturaleza. Fue un choque generacional que repentinamente se declaró insatisfecho ante las respuestas al uso, y se regodeó en las preguntas. Violentamente rescató el valor de la emoción como el núcleo del alma humana. Sus obras de arte evocan el retorno a cualquier tiempo heroico, con tal de dejar una protesta contra la mediocridad y la frivolidad. No sólo les decepcionó aquella educación y sus caminos del conocimiento - como al trágico Fausto-, tampoco mostraron interés por el poder político ni ganas de bien avenirse con sus gobiernos, ni de fijar lealtades a reyes o repúblicas. Sentían que en las minorías anida algo más sagrado que en las mayorías, y que detrás de determinadas derrotas hay algo más noble y honesto que un éxito vulgar. Las ideas no generan más ideas, sino que nos mueven a tomar decisiones. Carlyle considera, en On Heroes, que lo

1 En febrero de 1807 Niethammer le ofreció a Hegel el cargo de editor del Bamberger Zeitung, que hasta entonces había sido dirigido por el religioso francés Gerard Gley, refugiado en Bamberg desde 1791. Hegel amplificó la victoria francesa de Friedland y mostró admiración por la determinación con la que Francia parecía pretender modernizar a Alemania (Manfred Baum y Kurt Meist, «Politik und Philosophie in der Bamberger Zeitung: Dokumente zu Hegels Redaktionstätigkeit 1807-1808» en Hegel-Studien, 10 (1975), p. 91) 
más grande de un héroe es la verdad que encierra dentro de sí. Si no hubieran defendido una verdad o hubiesen sido testigos de lo falso, su dolor sólo nos hubiese movido a pena.

Frente al realismo pasivo y conformista que disecciona los objetos empíricos del mundo, el romántico buscó sumergirse en los parajes más profundos de la psique. Por eso mantenemos que el romanticismo tiene su origen en esta posición filosófica radical, y fue deudor durante más de una década de las obras de algunos filósofos que veremos a continuación.

Isaiah Berlin, en sus conferencias en la National Gallery of Art de Washington, en 1965, abrió todo el abanico de perspectivas y contradicciones siguiendo la obra de Arthur O. Lovejoy (Berlin 2000: 39), que tomó como rasgos de su estudio el primitivismo y el dandismo (Lovejoy 1941: 257-278). Lovejoy advirtió el placer que tenían por la vida sencilla y el retorno a la Naturaleza; tras ese goce estético subyace el empeño de justificar una ley natural, que ven más auténtica en el salvaje y en el niño no instruido aún. Es rebeldía contra todo.

Para Stendhal es lo moderno, y el clasicismo es lo apagado. Para Goethe era una «enfermedad», contra la que Hegel luchó como quien sale de su propio laberinto. Sus contemporáneos vieron el romanticismo como otra cabeza de la Hidra de la Revolución misma. Para Heine, fruto del Grial y un resurgir de la Poesía medieval. El marxismo vio un escapismo contundente contra la industrialización. Para Taine, el romanticismo fue el ariete de los nuevos arribistas burgueses contra la aristocracia superviviente del 89. En cualquier caso, no es la melancolía gimiente que pintaron los manuales, sino que expresa un optimismo radical.

\section{HAMANN CONTRA LA ILUSTRACIÓN}

Saber qué representó la Ilustración para el romanticismo interesa más que lo que signifique para nosotros. Las Luces inician aquello que la Filosofía analítica, en su inversión de la Metafísica, haría suya de otra manera; toda pregunta puede ser respondida racionalmente, y sobre la que no se pueda lo mejor es callar. Pero el romanticismo va a las preguntas que rompen ese límite. Tal vez nosotros no sepamos la respuesta, pero quizá «Alguien» la sepa. A lo mejor se supo en una edad de oro perdida, ¿o tal vez la edad de oro esté por llegar? Hegel prefirió exactamente esta última formulación, un saber absoluto como destino de la razón es algo que todos pueden compartir. Las condiciones que la Ilustración añadió no son menos baladíes: respuestas así son tan enseñables como el manejo de un artilugio técnico, es decir, se puede educar en los nuevos valores que emanen de esas verdades, y así del conocimiento mismo hicieron una virtud. Además, esas respuestas deben guardar una coherencia entre sí, de lo contrario estaríamos abocados al caos, sometidos a una Naturaleza dislocada. El modelo laplaciano imaginó la Naturaleza como un mecano, y 
nosotros mismos como otra pieza más entre tanto fragmento, cuya composición y descomposición una mente omnisciente sí conoce. Entre Newton y La Place se creó el consenso civilizatorio de que el orden de la Física y su deductivismo podrían extenderse a la política.

Para los Naturphilosophen, un grupo muy cohesionado a la sombra de Schelling y de von Baader, que llevaron las ideas románticas a las ciencias experimentales, el modelo newtoniano de la Física no era ni siquiera exportable al área contigua de la Química, el voltaísmo o la teoría del calor. Para Blake, sin mediar ninguna filosofía más, Newton y Locke eran el diablo en sus poemas.

Ya en plena Ilustración, Montesquieu resquebrajó con sus dudas el etnocentrismo de su época. Solo parámetros más pragmáticos que objetivistas explicarían por qué determinados valores funcionan en un sitio y no en otro. La segunda grieta la abrió Hume (Becker), su moral inspiró asociaciones como la Lit and Phil (Sociedad Literaria y Filosófica) de Edimburgo o de Manchester, que amplificaron sus ideas y sirvieron de encuentro a románticos como Coleridge.

Y, por último, el escenario final de ese ataque llegó de Alemania. En la atmósfera del pietismo quedó bajo sospecha la educación vigente, además de un desprecio por el despilfarro institucional, y puso su énfasis en la relación espiritual del alma con su Creador. Esta vena teológica es la que pocos años después Schleiermacher reconducirá a un cierto sosiego académico. Antes de esto, la labor de los fundadores del pietismo, Spener, Francke, Zinzendorf y Arnold, habían conseguido llevar alivio y salvación a muchos alemanes oprimidos y políticamente olvidados. Lessing, Kant, Herder y Fichte tuvieron un origen muy humilde, y la procedencia de Schiller, Schelling, Hölderlin y Hegel era también de clase media baja. Lo cierto es que, frente a los países mencionados antes, los desvertebrados Estados alemanes vivían años de complejo de inferioridad, de manera que el retraimiento hacia la interioridad tuvo algo de reacción defensiva. Por eso el combate abierto de Goethe, Schiller y Hegel contra el provincianismo de buena parte de las élites alemanas. El más firme exponente de estos ataques contra los ilustrados franceses fue J.G. Hamann, en cierta manera precursor de lo más instintivo del romanticismo. Vecino de Kant y protegido suyo. Su experiencia religiosa le sacó de sus derrotas y hasta de un conato de suicidio. Para él las vivencias narradas en el Antiguo Testamento, tienen también un valor universal para la humanidad. Su doctrina mantenía que las generalidades de las nuevas ciencias no satisfacían, cuando es la vida humana lo que se quiere captar. Dios, lejos de ser un astrónomo relojero, guardián de la geometría, es poeta de la palabra. Ninguna expresión artística es valiosa en sí misma, lo es sólo porque nos habla del ser humano. Para Hamann, la tendencia civilizatoria que conocemos, anegada por la burocratización, amenaza con convertir al hombre en una mustia flor de invernadero. 


\section{LA NATURALEZA COMO EDUCADORA. HERDER}

La moda de una religión basada en la razón había pasado. Ch. Wolff había dado desde la universidad alemana la versión más propia de esta síntesis de fe y razón. Fue el momento más propicio para sectas como la masonería y los rosacruces. Mesmer, en París, ofreció las más alucinantes ideas sobre el magnetismo animal. Los frenólogos viajaban aplicando sus terapias, y en algunos pueblos de Francia fueron enjuiciados por malas prácticas; para Hegel estos se convirtieron en su pesadilla particular, y en su Fenomenología del Espíritu ejemplificaban la nueva superstición de la pseudociencia. Después, en su época de redactor del Bamberger Zeitung, informó detalladamente de todas las denuncias contra ellos. En el extremo contrario, los Naturphilosophen buscaron dar forma científica al estudio del alma humana, incorporando los últimos descubrimientos del galvanismo. Lavater fue especialmente respetado por Goethe y el Sturm und Drang.

Hay un cierto desgarro fatalista que no es exactamente lo inevitable de los conflictos trágicos del Sturm und Drang, sino una convicción metafísica similar a la de Hamann, de que lo normal carece de la perspectiva suficiente para comprender lo que existe. Esta fuerza desviatoria irrumpe en el pensamiento contemporáneo con el romanticismo; en el fondo es -como la dialéctica hegeliana- una novedosa interiorización de la teología cristiana, la de un Creador más cercano a lo anormal que a lo estándar, la de Dios más próximo a enfermos, prostitutas y ladrones que a las teogonías versallescas o las teodiceas del clero disciplinado al Estado prusiano.

En Alemania, por entonces, no había escritor que no sintiera la influencia de Rousseau. F.M. Klinger, autor muy popular del Sturm und Drang, le hace escribir a un personaje de su novela Historia de un alemán de nuestros días, que el Emilio de Rousseau era el primer libro de los nuevos tiempos: «podía considerarse uno de los más puros discípulos de este evangelio de la Naturaleza». En parte era también un efecto del modelo de educación recibido. En Poesía, el acercamiento a la Naturaleza se hacía mediante Shakespeare; en filosofía moral con Rousseau. Desde jóvenes habían asimilado que en el proceso creativo hay algo más importante que la tarea de imitación y copia, y eso es el genio. Goethe, en 1771, celebrando la memoria del poeta, dice: «todo es naturaleza en los héroes de Shakespeare, y él ha creado hombres como Prometeo» (Goethe 1833: libro XIV).

El gran papel de la Naturaleza en la infancia fue también el principio básico de Basedow y Pestalozzi, auténticos revolucionarios de la pedagogía que ponen en práctica los ideales de Rousseau. Basedow fundó el instituto filantrópico de Dessau, haciendo de la instrucción un juego y valorando más que nada el esfuerzo del alumno (Pinloche 1839: 8). Pestalozzi abandonó sus estudios de 
Teología y Derecho, y entró en contacto con Bodmer y Lavater para fundar el «instituto agronómico y pedagógico» de Neuhof, en el cantón de Argovie, que es el que más aplicó lo que llamaron el método intuitivo, cogiendo la Naturaleza misma como estímulo. Asimismo serviría de ejemplo A. Hülsen.

Con más moderación que Hamann, Herder, discípulo suyo, también puso los ingredientes que necesitó el romanticismo: por ejemplo, que el hablar expresa enteramente la naturaleza humana. Está en sintonía plena con su coetáneo W. von Humboldt, para el que la lengua expresa no sólo a la persona, sino que constituye el alma de un pueblo (Volksgeist). La obra de arte es ante todo una voz humana que se dirige a nosotros. Por eso Herder añadió que separar a alguien de la comunidad a la que desea pertenecer es la primera de las alienaciones. Es indiferente el ser de la obra de arte, que a veces tiene un autor consciente, y otras es el legado inconsciente de un pueblo. Nadie se pregunta por la firma que hay tras las leyendas, el folclore o las normas morales que las costumbres consolidan. Los hermanos Grimm y Schlegel destacaron recuperando estas manifestaciones espirituales. Pero casi todos investigaron el sentido de ese inconsciente colectivo. La conciencia que despertó Herder causó en el romántico más dolor por el desarraigo y que se encaminara mentalmente de por vida hacia un «retorno a la patria». Con Herder percibían una singularidad que chocaba con aquel criticismo racionalista, pues elogia las cosas por lo que son, no las maldice por no ser lo que deben ser. La invención de los nacionalismos respondió a un malestar metafísico de este tipo, y Fichte será el creador filosófico de tal conclusión.

\section{De Kant a Schiller}

Kant, maestro de Hamann y Herder, detestaba el romanticismo por extravagante. Para Hegel, que creció militando en sus filas, se convirtió también en una pesadilla de la que apenas pudo despegarse. Pero, por ironías de la vida, Kant fue considerado uno de los inspiradores del romanticismo. Las diatribas contra la razón molestaban a Kant; él no sólo admiraba el rigor lógico y las ciencias naturales, sino que le gustaba considerarse también cosmólogo, ahí está como aportación su libro Teoría del cielo (1755). Aunque su verdadera preocupación fueron los impedimentos que encuentra la acción humana; una cosa es la cadena causa-efecto de la Naturaleza que nos rodea, y otra el obstáculo que los hombres ponen a su propio proyecto emancipador. Contra el determinismo espinosiano que sacudió las conciencias y escandalizó a la universidad, Kant afirma la libertad, la capacidad de elegir, como lo propio del hombre. La voluntad, pues, ilumina lo más específico de la moral. Por eso el argumento trivial de creer que hay mérito simplemente en elegir lo correcto, culpabilizar o reprobar a unos y elogiar a otros por la externalidad de sus acciones es algo que repugnaba a Kant. Ese mismo pensamiento, llevado a otro 
orden, se muestra como paternalismo político, justo lo que despreciaba de los gobiernos despóticos de Federico el Grande.

Esta introspección de la libertad es lo que entusiasmó a los románticos. Schiller, que estuvo entre los primeros lectores de Kant, llama directamente «independencia» a esta ciudadela interior de la libertad. Sobre esa noción fundó el romanticismo su teoría de lo trágico. La tragedia no consiste en narrar el morbo del sufrimiento - todo eso sería si acaso motivo de compasión-, sino que se da siempre que el hombre resiste. Cuando la resistencia se planta ante lo que oprime, sea de la naturaleza que sea, lo moral se llena de una dimensión nueva: la moral se constituye en el proyecto que somos, no en lo que hacemos. Es entonces cuando apela al compromiso y al reto humano. «Ser libre -les va a enseñar Kant- no es nada, ganar la libertad, en cambio, es celestial». Para Schiller hay posibilidad de retornar a una edad de oro, en la que aún no se haya escindido la libertad de la necesidad, ni la razón de la pasión; el medio es para él la educación estética. El atávico impulso al juego (Spieltrieb) permitiría ese retorno sin caer en lo naíf. Este giro es fruto de la filosofía idealista, que crea una novedad en la historia: los valores de una sociedad no se descubren por métodos científicos, ni siquiera por la «intuición», sencillamente se inventan.

\section{Fichte Y SCHeLLING}

En Fichte, la pregunta por el principio es fundamental: ¿qué es primero y qué es accesorio al pensar? Conocimiento y acción están en él completamente separados. La distinción entre estado de naturaleza y estado racional no deja de ser un convenio. Los salvajes, es verdad que se matan, pero las naciones civilizadas también. La cultura, en tanto que elaboración del conocimiento, la hemos sublimado como un freno a la violencia. Ahora el único freno posible será el que venga de la regeneración moral. Más que el ser o el deber, el hombre debe actuar. La acción es el principio de todas las cosas. El hombre que ni actúa ni crea, que se resigna a lo que la Naturaleza ofrece, no vive sólo pasivamente, está civilmente muerto. El idealismo en manos de Fichte enarbola esta rebeldía, es activismo. Y esto que se dice de un individuo vale también para los pueblos. Los Discursos a la nación alemana, escritos después de la humillación de Prusia por Napoleón, produjeron un enardecimiento nacionalista.

Schelling, en lugar de oponer a la Naturaleza la voluntad humana, lo que hace es partir de la Naturaleza de otra manera. Reelabora la noción de fuerza vital (Lebenskraft) que manejaban la Medicina y las ciencias experimentales de la época, y que les había transmitido la última edición del diccionario de J.S.T. Gehler [Gehler 1798: en la voz «Orgánica»]. Schelling la extiende, y va a ser propio de todo el movimiento romántico, al planeta entero, en línea con lo que estaba haciendo la buena Geología alemana del momento. En lugar de ver la Naturaleza como la veían los ilustrados, algo inerte y muerto que debe 
ser ortopédicamente reconducida, Schelling la explica como algo orgánico: la Tierra misma es un ser vivo que tiene una envoltura viva también, la atmósfera, es decir, el Alma del Mundo - título de su impactante libro de 1798-. Todo el proceso vivo e inconsciente de la Naturaleza está inserto en un desarrollo espiritual. Desde la «oscuridad», y pasando por varias edades, la Naturaleza llega a la consciencia gradualmente. Schelling llama «potencia» a estos pasos, que Hegel hará suyos también en sus primeras clases en Jena. Si las plantas son las potencias del orden anterior, el de los minerales (realidad inconsciente e inerte), y ellas a su vez se elevan a la potencia de lo animal, las creaciones del espíritu humano serían el siguiente grado sobre esa animalidad. La intensa confluencia de la voluntad fichteana y la «fuerza inconsciente» de Schelling dio con la mejor versión romántica del simbolismo. Pues, además de los símbolos convencionales, hemos de atender en el hombre a la expresión de ese impulso infinito de la Naturaleza como realidad espiritual. Hay un esfuerzo no culminado jamás, de expresar algo que sabemos inefable por inmaterial, haciendo uso de lo único que tenemos que son medios materiales, o sea, «elevamos» lo inconsciente a nuestro nivel de consciencia. Esto es lo más desafiante para un poeta. Esta profundidad infinita sobre lo aparentemente material es lo sagrado. Este apogeo de la experiencia romántica, desemboca en los dos sentimientos más angustiosos del romántico: o nostalgia o paranoia. Nostalgia, porque todo cuanto hagamos no nos dará la satisfacción de comprender el infinito. El Heinrich von Ofterdingen de Novalis pregunta a Cyane: «¿Adónde nos dirigimos?», y éste contesta: «siempre al hogar, hacia la casa del padre». Evidentemente es una respuesta religiosa, pero muestra la necesidad de subsanar esa falta con la incursión en lo extraño, que no es ni exótico ni extraeuropeo. Y paranoia porque sospechamos que hay algo detrás de esa oscuridad inconsciente de la Naturaleza o de su historia, a veces el rumbo de una «astuta razón». El hombre se busca chivos expiatorios, se imagina conspiraciones históricas o las reviste de nociones más metafísicas, como hizo Marx con la lucha de clases.

\section{LOS «AÑOS DE FORMACIÓN». HÖLDERLIN Y HEGEL}

El itinerario intelectual que seguían los estudiantes alemanes nos puede dar una idea del caldo de cultivo del que surgió el romanticismo. De niño, por ejemplo, Hölderlin pasó por la escuela monacal de Denkendorf, localidad cercana a su Nürtingen natal. Los Klosterschulen (escuelas monacales) eran hacia finales del XVIII un añejo recuerdo de los primeros años de la Reforma. El examen final de los dos cursos que hizo aquí consistió en un comentario al capítulo primero, «la verdadera revelación de Cristo», de la Epistola a los Hebreos. En 1786, pasó a la escuela conventual superior de Maulbronn. Allí se estudiaba latín, griego, hebreo, francés, poética, lógica, retórica, historia, matemática y metafísica. En su celda, Hölderlin leyó a Schiller y descubre a 
Ossián, del que dijo que está a la altura del mismísimo Homero. En realidad se trataba de un montaje literario perfectamente urdido; hoy sabemos que es un apócrifo que causó un gran impacto entre los jóvenes de toda Europa. James Macpherson dijo haber encontrado un poema épico escrito en céltico del siglo III por Ossián, que él tradujo y publicó: The Works of Ossian (1765). La traducción al alemán del austriaco Johann Nepomuk Denis culminó esas influencias.

Hegel fue el amigo en quien más confió Hölderlin siempre. En marzo de 1795, Hölderlin, refiriéndose a Hyperion - del que acababa de publicar un fragmento en la revista Neue Thalia dirigida por Schiller-, escribía a Hegel: «habré acabado la novela para Pascua; déjame hasta entonces que no hable de ella». Lo que no sabía todavía Hegel, es que por esos meses el crepúsculo de la enfermedad había caído sobre la cabeza del poeta. Sólo la hospitalaria amistad de von Sinclair lo acogía en medio de esa deriva. La «masa cruda» del Hyperion-decía su autor-se quedaba sin un final. Pero como novela subvertía muchos más cánones de los que tenía el relato al uso. Ellos compartían, como comparten los jóvenes sus inquietudes, una educación reglada bajo el modelo de la novela de formación (la Erziehungsroman o Bildungsroman), en las que se cuenta linealmente la evolución interior de una persona. Desde Wieland o Goethe hasta Jean Paul o Novalis, son muchos los autores que la cultivaron. Con mayor o menor sesgo psicológico, Hyperion, que asemeja en cierta medida esa moda, rompe la evolución del sujeto en dos fases: el tiempo de la nostalgia y el tiempo de la memoria. El protagonista recuerda su evolución, y mientras recuerda sigue evolucionando a mejor. Pues bien, Hegel atrapa esa categoría directamente para el pensamiento, el pensamiento que piensa acordándose de sí mismo y de lo pensado. Hyperion rompe lo genuino de la Erziehungsroman de llegar a la madurez psicológica, y lo sustituye por la búsqueda de un equilibrio entre personaje y entorno (Naturaleza, principalmente, más que civilización). Frente a la tópica linealidad, Hölderlin recurre al curso de una «órbita excéntrica»; una metáfora que cualquier interno de Tubinga entendía de primera mano: era la otra armonía, ni simple ni circular, descubierta por Kepler sobre los movimientos planetarios alrededor del Sol. A lo largo de su curso hay momentos con que se logra ese equilibrio y otros en los que se pierde. Hyperion recuerda su «cercanía al centro» (la infancia en la isla de Tina, su maestro, los años vividos frente al mar de Salamina y el amor de Diótima) y también su alejamiento del astro rey (aprender en la escuela que le «expulsó del jardín de la naturaleza», la turbación de la adolescencia, el nihilismo, «hemos nacido para nada, nos esforzamos para nada», el furor y la violencia con que combatió a favor de las tropas libertadoras y la muerte de Diótima). Precisamente por concebir la trama como una serie de disonancias, como otra evolución que se afianza sobre episodios de equilibrio y estallido, la historia no podía tener una 
final feliz; es más, no podía tener un final. A Hölderlin le aterrorizaba el lector deseoso de subrayarse una moraleja.

Hegel concibió sus lecciones de Filosofía de la Naturaleza y del Espíritu exactamente de la misma manera, una transgresión del tiempo del relato, y termina también en un callejón sin salida. La curiosa protagonista apenas la reconoceríamos, pero es la Naturaleza misma, o en todo caso la Tierra que nos alberga: el «curso excéntrico» de su evolución asume esa polaridad y tensión. A cada paso que se eleva sobre lo inerte o lo orgánico, en una jerarquía de potencias, una dialecticidad lógica le sirve de fuerza. Aquí tampoco se trata de una maduración plana, sino más que el día de llegar a ser adulta, en la Naturaleza hay episodios de muy densa y calibrada reflexión sobre sí, en los que brota la vida con la misma suerte (negatividad y polaridad): la sensación y hasta la inteligencia, o figuras civilizatorias como el trabajo, o la memoria de una nación. Hegel recapitula la epopeya de la Naturaleza y sobrepone la vida, el tiempo de la Orgánica, a todo lo pasado. El antes y después no va a ser medido por movimientos mecánicos ajenos a nosotros, sino como los pasos de la podredumbre y el envejecimiento.

Sin embargo, Hegel no es consciente de estas similitudes con el compañero, ni de este contagio del romanticismo y del fichteanismo. Sólo esa inconsciencia hacía inofensivas sus clases, como fue su trabajo docente desde el semestre de 1803/04 hasta 1806, pero el modelo que ofrece a aquellos pocos jóvenes, con la arquitectónica entera del curso, es la Naturaleza como Bildungsroman, sin más trazas de subjetividad que las que con sarcasmo nos ofrecen las plantas. El vértigo fichteano es ahora, en el díptico de un semestre, el paso del No-Yo al Yo, la atormentada escisión entre las tinieblas y la luz, el destino y la sabiduría, en fin, la Naturaleza y el Espíritu. Salió de su pluma no con los aires de su benefactor, Goethe, sino con los de esta tragedia del amigo. Hölderlin huyó de Jena; Hegel tampoco sabía todavía que él terminaría haciendo lo mismo. El poeta se llevó consigo, de entre las ausencias de la ciudad, lo más titánico de Fichte, y tras una y otra versión, la segunda parte de la novela se publicó en octubre de 1799. En ese cabalístico final de siglo, Hölderlin se hunde en otra frustración, la esperanza que había puesto en que los franceses le liberaran del destino de su propia patria, se veía ahora tan helada y marchita como los ideales de la Revolución.

El 11 de septiembre de 1806 Hölderlin era tratado de sus dolencias por Autenrieth, autor que menciona Hegel ese mismo año en esas lecciones jenenses que referimos (Realphilosophie) criticando su burda visión mecanicista-tenía motivos para hacerlo-. Hegel sigue la edición de 1801 de su tratado de Fisiología a propósito de la respiración y de los efectos del aire sobre la sangre. Autenrieth prácticamente estrenaba su clínica con Hölderlin, en Tubinga también, ciudad donde ya era profesor de Fisiología; su fama le vendrá luego del cargo 
de canciller que ejerció en la universidad y de la Medicina legal que en parte funda en Alemania, porque lo que es de psiquiatra resultó ser un desastre, y con Hölderlin no mostró ni la más mínima pericia. El poeta había sido encerrado y sometido a un tratamiento de grandes dosis de opio y digital. Finalmente dictaminó que su locura era incurable, pero que podía vivir en libertad.

\section{EL TÜBINGER STIFT}

Pero regresemos a los mejores años de sus vidas juntos. El Stift de Tubinga había sido fundado, en 1536, por el duque Ulrich von Wüttenberg para enseñar el nuevo credo de Lutero. En sus aulas coincidieron Hölderlin, Schelling y Hegel, que con sus múltiples facetas cubren casi todas las perspectivas del romanticismo. Estuvieron allí entre los 18 y los 23 años. Al terminar empezaban una disciplinada trayectoria con algún destino lejano en alguna parroquia. Así, el encargo profesional como preceptor (Hofmeister) de una familia acomodada, servía para prorrogar esa carrera eclesiástica. Hölderlin fue a Waltershausen, Hegel a Berna y Schelling a Leipzig. Este seminario de Tubinga lo dirigía un Ephorus, que solía ser siempre un destacado teólogo, por entonces era el pastor Christian Friedrich Schnurrer, un hombre afable que se quedaba al margen de las polémicas teológicas de la época y se ceñía a exégesis etimológicas. Había dos tipos de clases, las locus y las repetitiones. Las primeras eran explicaciones que seguían estrictamente el manual, párrafo a párrafo; las repeticiones eran más flexibles, además de estar encomendadas a Repetenten, jóvenes seminaristas que acababan de licenciarse. El plan de estudios estaba especializado en Filosofía, lenguas clásicas y música sacra. Recibieron clases de Ch. Rössler (Historia de la Iglesia) y de J.F. Flatt que dedicó el curso al De natura deorum de Cicerón. En Hölderlin influyeron especialmente Repetenten como Ch.G. Bardili y C.Ph. Lonz. El primero innovó en el uso de la literatura para la predicación, y el segundo se centró en las tragedias de Sófocles. Pero más decisiva fue la influencia de C.I. Diez, un vehemente kantiano que logró acabar con la aversión oficial del Stift contra Kant. Hegel recuerda también afectuosamente a Pfleiderer, el profesor de matematicas, experto en todas las traducciones habidas sobre los Elementos de Euclides.

La vocación poética de Hölderlin se rearfirmó por la convivencia en el patio del Stift. La amistad con Ch. Neuffer y R. Magenau les llevó a crear la alianza poética (Dichterbund) que bautizaron como Aldermannsbund; el término inglés aldermann significa edil. Los tres jóvenes poetas se veían como los dirigentes de una república utópica. La ingeniosa idea la tomaban del ensayo de Klopstock la República ilustrada (Gelehrtenrepublik). Neuffer fue destinado como párroco a Wertheim y Ulm, y tradujo la Eneida al alemán.

Grecia se convirtió para Hölderlin, en parte por influencia de Schelling, en símbolo de libertad y belleza. Schelling era el más joven del grupo. El paseo 
favorito de ellos era por las afueras de Tubinga hasta la Wurmlingen Kapelle, una ermita barroca en lo alto de una colina rodeada de viñedos, a la que se subía por un ondulado vía crucis del siglo XVII. En el poema Eleusis, que Hegel dedica a Hölderlin -del que iba a ser gran filósofo al que iba a ser gran poeta-, se trasluce el panteísmo que compartían: «en la inmensidad soy todo, solamente soy», «la fantasía acerca lo eterno a los sentidos». Franz Rosenzweig, en 1913, publicó un documento manuscrito por Hegel: El primer programa de Sistema del idealismo alemán (Das älteste Systemprogramm des Deutschen Idealismus); desde entonces es cuestión abierta la autoría del mismo, es muy probable que fuese Hölderlin su autor:

Quiero advertir que la idea de Estado no existe, porque el Estado es algo mecánico, y no existe ni la idea de Estado ni la idea de máquina. Sólo lo que es objeto de libertad se llama idea. Por tanto, ¡tenemos que superar también el Estado!

Por primera vez el intelectual no reconstruye la tradición -que en este caso se remontaría a la Filosofía política del Renacimiento-para reforzar una idea, ni siquiera para contrastarla con el remozado organicista que le dio Kant, sino sencillamente para destruirla. Ya vimos que el romanticismo se movió como una selva de contradicciones, y en los retazos políticos es todavía más evidente. En las regiones alemanas más afrancesadas, los románticos fueron vistos como agentes reaccionarios; las mismas actitudes y argumentos en Prusia se percibían como revolucionarias. Las diferencias entre los jacobinos y los girondinos se reflejaban tal cual en las universidades alemanas. Entre 1793 y 1794, cuando Novalis está en Wittenberg por empeño de los padres en que sea abogado, y Hölderlin y Hegel plantan el árbol de la libertad en Tubinga, el 14 de julio, ajusticiaron a Luis XVI y a Robespierre. La primavera del Terror con miles de ejecuciones sumarísimas, arbitrarias y políticamente interesadas, conmovió a todos. Los estudiantes empezaron a sentir una confusión inesperada ante los planes de la razón que habían aprendido, o porque la libertad y la violencia vinieran siempre del mismo lugar. A partir de aquellas fechas, Hölderlin, que se había sentido uno más entre los jacobinos alemanes, pierde sus esperanzas en la Revolución francesa. Hasta muy poco antes, Schelling, de preceptor en Leipzig nada menos, había hecho circular su traducción de la Marsellesa. La exaltación que Hölderlin mostró en los Himnos de Tubinga se torna decepción en la carta a su hermano Carl, del verano de 1793:

[Hay] un mundo mejor en camino. La sagrada meta de mis deseos y mis actos es esta: despertar en nuestro tiempo la semilla que madurará en el futuro. 
Lo que sí es común a todos los románticos es que esa decepción se vuelca contra su propio país. A Neuffer le escribe: «Los alemanes no están a la altura». Y en el poema An die Deutschen dice de los alemanes: «ricos en ideas y pobres en acciones» (Pau 2008: 60-61). La «República de Suabia», que soñó en su ideario como la siguiente ficha que seguiría a Francia, había dejado de ser un objetivo.

\section{Novalis}

En la trayectoria de Novalis hay un hecho que pasa desapercibido en los manuales de literatura, insignificante si no fuese por lo importante que es en la génesis del romanticismo. Novalis, que estudiaba en Leipzig en unos momentos muy agitados por la invasión francesa de Austria, conoció a Friedrich Schlegel, estudiante de Filología, él era entonces de Jurisprudencia y Filosofía -así se lo contó en carta a Reinhold, su antiguo profesor de Filosofía en Jena y artífice del kantismo que propagó esta universidad-. Schlegel percibió enseguida la inteligencia y exuberancia de Novalis, que tiene presente en su pensar no la verdad sino la belleza - como le contó a su hermano mayor August Wilhelm Schlegel, por entonces en Holanda-.

Friedrich Schlegel conocía perfectamente la Antigüedad clásica, y abrió una perspectiva nueva en Novalis. La amistad entre ellos fue muy grande. El vocablo «romántico» lo acuñan ellos en ese contexto, pues el movimiento anduvo antes disperso, o en todo caso aglutinado bajo el Sturm und Drang y el vigilante Goethe. Fue sólo para calificar un cierto sentido poético:

Romantizar no es sino una potencia cualitativa. En esta operación, lo más bajo adquiere el rango de lo más elevado. [...] Se trata de dar a lo corriente un sentido superior, a lo vulgar un aspecto misterioso, a lo conocido la dignidad de lo desconocido.

Así dice Novalis, para quien romantizar el mundo consiste en la elevación o la absolutización del momento. Lo infinito es el misterio que recubre las cosas. A menudo sólo nos topamos con cosas, pero para el espíritu no hay nada más al alcance que el infinito (Pau 2010: 23-24). Romantizar es un viaje hacia el universo interior que hay en nosotros mismos.

Novalis inició sus estudios universitarios en Jena. La familia aceptó esa elección porque allí estaba Schiller como profesor de Historia. La admiración personal, más que literaria, que sentía por Schiller fue enorme. Durante el curso que fue su profesor explicó las Cruzadas. Los estudios de Derecho que allí debía seguir no le atraían lo más mínimo; para sus padres era la condición para conseguir un alto cargo entre la burocracia sajona, dada la procedencia aristocrática de la familia: los von Hardenberg. Años después de acabar sus 
estudios en Wittenberg, escribe en uno de sus fragmentos: «soy ajurídico, sin ningún sentido ni necesidad del Derecho». En Jena se entusiasmó también por las clases de Reinhold, un exjesuíta que había sido profesor también de Fichte, Hegel y Schelling; quizá sin su enfoque del kantismo no hubiese surgido nunca el idealismo. Cuando Novalis empezó a trabajar en la secretaría de Tennsted, a las órdenes de August Coelistin Just, gran jurista y amigo de la familia, retoma su vocación de poeta. Por entonces conoció a Sophie von Kuhn, diez años menor que él. A Schlegel le escribe: «Mi estudio preferido se llama como mi novia [...]. Filosofía es el alma de mi vida, la llave de mi mismo». En carta a su hermano Erasmus, de noviembre de 1795, le cuenta cómo ocupa su tiempo libre en Tennsted: «Me dedico al ejercicio necesario de mi capacidad filosófica».

Es el momento en el que escribe su largo estudio sobre Fichte. Se dedica a «fichtear»-como decía humorísticamente que hacían los jóvenes de su generación-. Novalis y Hölderlin fueron alumnos de Fichte en Jena. Fichte les miraba a los ojos en clase y les planteaba la escisión metafísica entre el Yo y el No-Yo, en la que el No-Yo era el resultado de la capacidad de representación del Yo, y sobre todo que la primera acción del Yo era conquistar la libertad de pensar por sí mismo.

Después de Fichte, en 1797, Novalis lee a un filósofo holandés afincado en Alemania que escribió toda su obra en francés: Hemsterhuis. En el diálogo Alexis o la Edad de Oro, el hombre posee un sexto sentido, que a veces indicamos con las palabras corazón o conciencia, y que él llamó «órgano moral»; éste nos permite percibir entre la multiplicidad de la Naturaleza un orden armonioso. Para Hemsterhuis es la raíz común de lo bello y lo bueno. Y pese al espinosismo que hay detrás de estas ideas, los románticos reconocieron que éste es el órgano que más nos acerca a Dios y la Poesía su lengua de comunicación.

\section{LA NATURPhiLOSOPHIE}

En 1797, Schelling, ya catedrático de Filosofía en Jena, publica Ideas para una Filosofía de la Naturaleza. La influencia de esta obra es grandísima en ese momento. Novalis y Hegel están entre sus lectores; los doctorandos de Schelling y sus seguidores van a convertirse en la vena más naturalista y experimental del romanticismo: Steffens, Ritter, Röschlaub y Marcus, Pfaff, Eschenmayer, von Schubert, Carus, etc. Fisiólogo, químico que trabajó con la pila Volta recién instalada en Jena, expertos en Embriología y Obstetricia del hospital de Bamberg, físico del magnetismo y traductor del médico escocés John Brown, teórico de la enfermedad, botánico y pintor respectivamente. Todos ellos, incluido Schelling, sentían la cercana atracción de Freiberg. Su Escuela de Minas, en el corazón de la ferruginosa y carbonífera cuenca del Harz, había conservado un modelo de educación elitista. Bajo el patriarcado científico del gran Werner, muy apreciado también en Gran Bretaña, Freiberg 
se convirtió en el gran santuario de la Naturphilosophie, y desde allí irradió sus ideas a Weimar, Gotinga, Jena, Leipzig y tantísimos profesionales que no perdían oportunidad de ponerse al día en sus aulas. Werner en Mineralogía, Lampadius, discípulo del fallecido Lichtenberg, entonces gran sabio de la Física y la Meteorología en Gotinga, Weiss, traductor de Haüy, gran minerólogo francés, etc. Novalis se las arregló para obtener un permiso de la administración sajona para estudiar en Freiberg. A fin de cuentas, el negocio del subsuelo era el único en el que la familia del barón von Hardenberg dependía de sí misma. La familia tenía la concesión de las minas de Wiessenfels y las salinas de Kösen. Además acompañó al Consejero de Finanzas von Oppel en las inspecciones a las minas de Dürrenberg y Artern. En Freiberg, Novalis escribió su Repertorio general (Allgemeiner Brouillon), lleno de datos y conocimientos científicos, un texto que debería haber culminado en una Enciclopedia; en realidad este tipo de escritura se trataba casi de un género pedagógico que registraba todo un itinerario de formación: se comenzaba con los extractos (Exkerpten) y podía llegar a madurar en la Enciclopedia. Años después, con más tardanza vital, Hegel sí culminó su Enciclopedia de las ciencias filosóficas (Heidelberg, 1817). Lo que sí acabó Novalis fue su novela Los aprendices de Sais. Para el protagonista, el maestro, se inspiró en Werner. Sais, la ciudad egipcia, es donde estaba el templo de Isis; desnudar a la diosa, o la Naturaleza, era la tarea de desvelamiento de la nueva ciencia. La Naturphilosophie también fue productiva en otras áreas de la ciencia como la Embriología o la Botánica. Goethe acuñó el término «Morfología» para referirse a la probable existencia de un patrón común de los que derivarían las múltiples formas de plantas o insectos. Pero la teorización de la ingente cantidad de datos de observación de la Naturaleza fue un mérito colectivo de toda esta generación del romanticismo. La Naturphilosophie, con sus aciertos y errores, se convirtió así en la personificación científica del romanticismo, y es responsable del biocentrismo del que apenas se ha movido nuestra cultura. Haller y Bonnet habían dejado un legado muy influyente. Bonnet había investigado la regeneración de las lombrices, la respiración de los insectos, y descubrió la partenogénesis en áfidos. Su Contemplación de la naturaleza (1764) es leída e interpretada por la Filosofía del momento. Y en la Palingénésie philosophique (1769) habla de la evolución de organismos ya preformados en el germen. El concepto de «generación repetida» (palingénesis) lo tomó Haeckel para indicar que se da una recapitulación de la filogénesis en los estadíos de la ontogénesis, es decir, los cambios de formas previas al nacimiento [Gould 2010: 30]. Esta filosofía de Bonnet, que abarca desde un microorganismo suspendido en una gota de agua hasta la naturaleza de Dios, es asumida por el romanticismo como «la gran cadena del ser»-la expresión es de Lovejoy, 1936-. Más prosaicamente, la Naturphilosophie recurrió a la creencia y a la intuición en la unidad de la Naturaleza y de sus leyes. Un orden 
universal con validez metafísica en el que el Espíritu surge como conclusión de la Naturaleza, y en la que el hombre ocupa un puesto compatible al menos con una visión transcendente de la vida. Kielmeyer, maestro de Cuvier y elogiadísimo por Schelling, fue el primero en aplicar la recapitulación, como teoría general, a la Morfología. Cuando ya el romanticismo empezaba a hacer historia de sí mismo, Novalis muerto y Hölderlin sumido en la enfermedad, Lorenz Oken publicó en tres tomos su Manual de Naturphilosophie (18071811), que fue objeto de todos los ataques y origen de la mala reputación que la ciencia dominante del XIX vertió sobre la Naturphilosophie como ensueños especulativos e irracionales. Oken fue, sin embargo, un magnífico anatomista. Serres fue el mayor defensor con que contó la Naturphilosophie en Francia, incorporó con habilidad la noción de fuerza vital a la teoría de la recapitulación, observó que las deformaciones surgidas por debilidad de fuerza vital se parecían a los estadios adultos de organismos inferiores. Hegel, a diferencia de Fichte, contempló el Absoluto como una retrogresión de la Orgánica, en la que a su vez se supera lo inerte y mineral. Oken ejercía una influencia fascinante sobre sus alumnos. Louis Agassiz, científico norteamericano que asistió a sus clases, así lo atestigua (Gould 2010: 56).

\section{El absoluto en literatura. Tieck y los Schlegel}

Tieck publicó una selección de obras dramáticas con el título Poemas románticos (Jena, 1799/1800); el término aludía al carácter fabuloso de una trama. En el prefacio a los Cantos del Minnesinger aus dem schwäbischen Zeitalter (Berlín, 1803) llama «romántica» a la Poesía narrativa del siglo XVIII: «el amor, la religión, la caballería y la magia se unieron entonces [...] y se confundieron en una epopeya maravillosa». F. Schlegel, en cursos que explicó hasta 1811, presentaba lo romántico como un germen que surgió en una sociedad aristocrática y feudal que se perpetúa indefinidamente, y es por donde se expresa una civilización cuando finisecularmente se aboca a sus propios disparates. Esta generación es una inflexión finisecular en la cultura, en la que la civilización se sojuzgó a sí misma.

La revista Athenaeum fue el órgano de expresión del prerromanticismo. Había surgido a fines del XVIII cuando todavía estaba en auge el clasicismo de Wieland y el Sturm und Drang de Klinger o Bürger. Además de servir de eco a la Revolución francesa, se impregnó de la idea de autoperfeccionamiento que nos lleva a la plenitud y de la convicción de que todo (ciencia, arte y las actitudes cotidianas) está imbuido de la Poesía, es decir, del Absoluto. Todos los que escribieron en el Athenaeum forman la mayor parte del movimiento prerromántico; no están Hölderlin ni Jean Paul; pero, en aquél otoño de 1799, en Jena, están juntos los Schlegel, sus influyentes esposas Carolina Michaelis y Dorothea Veit, Schelling, Tieck y Novalis. Y en un plano más discreto, 
Schleiermacher, Steffens, Ritter y Hülsen. Steffens también había tenido una exquisita formación científica en Freiberg. Poeta igualmente, en carta a Tieck sentencia muy bien lo que fue el destino del romanticismo, y, a la vez el signo de la Filosofía del XIX: «soñábamos juntos, eran tiempos plenos de proyectos de todo tipo, pero había un germen de destrucción en el fondo de todo eso. Lo que hicimos fue levantar una Torre de Babel espiritual».

\section{El SUBCONSCIENTE}

En los estados latentes de la Naturaleza encontró el romanticismo, como conciencia dormida, la conciencia moral. El je pense cartesiano había inaugurado la era en la que la razón se autodescubre a sí misma, y por causa de ella un mundo mágico que pervivió hasta el Renacimiento se descompuso con la misma violencia que la arcabucería de las guerras de religión. Entonces Leibniz rechazó esa extrema división entre lo claro/distinto y lo oscuro/confuso. Matizó una gradación entre ambos: una mónada espiritual que de suyo se programa teleológicamente hacia la claridad. En ese trayecto surgen formas inconscientes que por esa metamorfosis invisible llegan a la claridad. Kant ignoró esta génesis leibniziana de la subjetividad. No hay inmediatez en la percepción de sí mismo -le dirían a los cartesianos-, sino que esta está mediatizada por el curso temporal de todas las cosas de la Naturaleza. Nicolai Hartmann, en $L a$ Filosofía del idealismo alemán, advierte del cambio que supuso extrapolar esta reflexión al orden de la libertad. ¿Qué pasa con un sujeto así ante el orden práctico? Descartes y Kant ocultaron las vergüenzas de lo subsconsciente. El romanticismo retornó a Leibniz y rehizo su camino.

Para Fichte, en el acto de libertad, al darse el hombre leyes a sí mismo, puede que estemos por descubrir una trama que transciende las condiciones de finitud del sujeto teorético; así se dará con el fundamento absoluto que supere esta escisión, y será esa metamorfosis, la que dote de verdad y protagonismo al camino del saber en tanto que saber mismo. En Fichte esto se caracteriza como Sistema, y alude a una articulación organicista de las partes con el todo, a un ser vivo. «Sistema», por tanto, en el romanticismo de Schelling y Hegel, es una alternativa a la concepción mecanicista y cosificada de los saberes. Por eso, del estudio del reino de la libertad entendieron que debía pasarse a la filosofía de la Naturaleza (Yepes 2010: introducción). Ya antes en la Naturaleza dormía un mundo espiritual. Los fenómenos sobre el límite indefinido entre lo mineral y lo vegetal, entre lo vegetal y lo animal, recibieron desde entonces una atención especial: el magnetismo, por ejemplo. Goethe lo había anunciado con sus «fenómenos originarios» (Urphänomen). Es el viaje de Fausto hacia el país de las matrices o duramadres. A lo largo de una sobresaltada evolución se van formando especies, y lo que se ve como perfecto en una especie, pronto queda 
superado en la siguiente como un rasgo infantiloide que pasa a uno análogo adulto en la especie siguiente.

\section{REFERENCIAS BIBLIOGRÁFICAS}

BECKER, C, Heavenly City of the Eighteenth-Century Philosophers. Yale University Press, ${ }^{2} 2003$

BERLIN, I., Las raices del romanticismo (edición de H. Hardy), Taurus, Madrid, 2000

CARLYLE, Th., Essais choisis de critique et de morale: caractéristiques, Burns, Jonson, Goethe, sur l'histoire, signes des temps. Société de Mercure, París, 1907

—, Los héroes: culto a los héroes, lo heróico en la historia. Rubio, Madrid, 1932

COLERIDGE, S. T., Biografia literaria. Pretextos, Valencia, 2010

DILTHEY, W., De Leibniz a Goethe, FCE, Méjico, 1945

GEHLER, J.S.T., Physikalisches Wörterbuch, Leipzig, ${ }^{2} 1798$

GOETHE, Poesía y Verdad: de mi vida, Alba, Barcelona, 1999, libro XIV

GOULD, S.J., Ontogenia y Filogenia, Crítica, Barcelona, 2010

HARTMANN, N., La filosofía del idealismo alemán, Zucchi, Buenos Aires, 1960

LOVEJOY, A.O., «The Meaning of Romanticism for the Historian of Ideas» en Journal of the History of Ideas (1941), 2

- The Great Chain of Being. Havard, 1933

PAU, A, Hölderlin. El rayo envuelto en canción. Trotta, Madrid, 2008

—,Novalis. La nostalgia de lo invisible, Trotta, Madrid, 2010

PINLOCHE, La réforme de l'Education en Allemagne, París, 1839

YEPES, J.L., De la «Naturphilosophie» al Sistema de la Ciencia: La revista de L.W. Gilbert en Hegel. UNED, Madrid, 2010

- Hegel lector de Gilbert. Las ciencias experimentales del romanticismo, EAE-Lampbert, 2011

José Luis Yepes Hita es Doctor en Filosofía (Madrid, 2009). Licenciado en Filosofía y Ciencias de la Educación (Universidad Central de Barcelona). El título de su tesis es De la Naturphilosophie al Sistema de la Ciencia. La revista Annalen der Physik de L.W. Gilbert en Hegel (Jena 1803-1806). Dirigida por José María Ripalda y calificada con Sobresaliente cum laude.

Publicaciones recientes

Hegel lector de Gilbert. Las ciencias experimentales del romanticismo. EAE-Lampbert, Saabrücken, 2010

«Los Anales de Física de LW Gilbert y su influencia en la Naturphilosophie de Schelling y Hegel», en Naturaleza y Libertad. Revista de Estudios Interdisciplinares (2012) no 1, p. 171

«Caravaca de la Cruz en la revista Annalen der Physik (1803) y la consolidación científica 
de la Mineralogía y la nueva Química» en ANDELMA. Revista del Centro de Estudios Históricos, año IX, número 22, Cieza, Diciembre 2013, pp.28-33

Dirección electrónica: jlyepes@um.es; jlyepes@yahoo.es 